\title{
A STUDY ON MEDICAL FITNESS OF UNDERGRADUATE MEDICAL STUDENTS WITH REFERENCES FOR FURTHER IMPROVEMENT OF THEIR HEALTH
}

\author{
Amit Kumar Ghosh', Mausumi De2, Anup Das 3 , Subrata Das ${ }^{4}$, Sudip Barua ${ }^{5}$ \\ ${ }^{1}$ Associate Professor, DepAmith Kumar Ghosh-naga-(ranjitha)Shru (OR) July 31-Checkedartment of Pharmacology, R. G. Kar Medical \\ College. \\ ${ }^{2}$ Associate Professor, Department of Pharmacology, R. G. Kar Medical College. \\ 3 Professor and HOD, Department of Pharmacology, R. G. Kar Medical College. \\ ${ }_{4}^{4}{ }^{\text {nd }}$ Year Postgraduate Trainee, Department of Pharmacology, R. G. Kar Medical College. \\ $52^{\text {nd }}$ Year Postgraduate Trainee, Department of Pharmacology, R. G. Kar Medical College.
}

\begin{abstract}
\section{BACKGROUND}

The medical students undergoing MBBS course are busy all the time in their lessons and other academic activities. There is hardly any time of taking care of their health and they are reluctant to exercise. They also suffer from various mental stress and strain in their long study periods. So, after passing out, they may lose their firmity and may be a victim of chronic diseases like hypertension, diabetes, obesity, etc. So, it is very urgent to do some interventions to maintain the physical and mental health of the medical students, as they are the future healthcare providers of our society.

Our primary aim was to find out the different health problems among undergraduate medical students. The objectives were to find out the causes of absenteeism in the classes and take opinion from the students for improvement of their health status.
\end{abstract}

\section{MATERIALS AND METHODS}

A cross-sectional study was conducted to understand the present scenario of the health status among the undergraduate medical students of $3^{\text {rd }}$ year MBBS batch in a medical college at Kolkata. The survey was questionnaire-based study among the students containing 15 questions and also their own suggestions for betterment of their health. Questions were prevalidated by faculty members and response of the students were analysed by statistical methods.

\section{RESULTS}

Out of 198 students in the class 148 students (Response rate 74.7\%) took part in the study, of whom 105 were male and 43 were female. It was found that only few students did physical exercise daily and few practiced yoga on a regular basis. It is also seen that most of the students had got sick and there was a large number of sickness absenteeism in the last year. Most of the students gave their opinion for recruitment of yoga or physical instructor in the college and need of a gymnasium.

\section{CONCLUSION}

It is concluded that lack of regular exercising may cause infirmity and ill health in medical students. Now, it is the prime need for starting of gymnasium and recruitment of gym and yoga instructor in every medical colleges to look after the health of medical students for a bright future.

\section{KEYWORDS}

Medical Fitness, Undergraduate Medical Students.

HOW TO CITE THIS ARTICLE: Ghosh AK, De M, Das A, et al. A study on medical fitness of undergraduate medical students with references for further improvement of their health. J. Evolution Med. Dent. Sci. 2017;6(61):4441-4444, DOI: $10.14260 /$ Jemds/2017/960

\section{BACKGROUND}

Physical fitness is a general state of health and well-being and more specifically the ability to perform aspects of sports, occupations and daily activities. Physical fitness is generally achieved through proper nutrition, moderate-to-vigorous physical exercise and sufficient rest. $[1,2,3]$

A holistic definition of fitness is described by Greg Glassman in the Cross Fit Journal as an increased work capacity across broad times and modal domains; mastery of

Financial or Other, Competing Interest: None.

Submission 24-01-2017, Peer Review 18-07-2017,

Acceptance 24-07-2017, Published 31-07-2017.

Corresponding Author:

Dr. Amit Kumar Ghosh,

\#38, Biprodas Chatterjee Lane,

Howrah, West Bengal.

E-mail: dyregistraramitghosh@gmail.com

DOI: $10.14260 /$ jemds $/ 2017 / 960$

\section{(c) $(1) \odot$}

several attributes of fitness including strength, endurance, power, speed, balance and coordination and being able to improve the amount of work done in a given time with any of these domains. ${ }^{(4)}$

The Americans Physical Activity Guidelines suggest that all adults should avoid inactivity to promote good health mentally and physically. For substantial health benefits, adults should participate in at least 150 minutes a week of moderate-intensity or 75 minutes ( 1 hour and 15 minutes) a week of vigorous-intensity aerobic physical activity, or an equivalent combination of moderate- and vigorous-intensity aerobic activity. Aerobic activity should be performed in episodes of at least 10 minutes, and preferably it should be spread throughout the week.

Adults should also do muscle strengthening activities that are moderate or high intensity and involve all major muscle groups on 2 or more days a week, as these activities provide additional health benefits.[5] 
Cardiorespiratory fitness can be measured using VO2 max, a measure of the amount of oxygen the body can uptake and utilise.[6][7] Aerobic exercise which improves cardiorespiratory fitness involves movement that increases the heart rate to improve the body's oxygen consumption. This form of exercise is an important part of all training regimens ranging from professional athletes to the everyday person. Also, it helps to increase stamina. Examples are jogging, walking, swimming, cycling or treadmill training. There are other various benefits of physical exercises like blood pressure control, cancer prevention,(8) reduces inflammation, boosts immune system,(9) weight control,(10) cardiovascular disease prevention, etc.

Maintaining a healthy lifestyle and sticking to a proper nutrition plan in college period can be challenging, especially if the student does not know how to cook or tends to grab items on the go. So exercise and proper nutrition is the only way to maintain a healthy weight, stay focused and productive on those long days and nights of studying and attending classes.

The medical students undergoing MBBS course are the future healthcare providers of our society. They are engaged all the times in reading books, journals, working on computer and practical classes and busy in examinations, part completion and other various academic activities. There is hardly any time for taking care of their health. They also suffer from various mental stress and strain in their long study periods. So after passing out they may lose their physical strengths, firmity and may be a victim of chronic diseases like hypertension, diabetes, obesity, etc. So it is very urgent to do some intervention to maintain the physical and mental health of the medical students.

\section{Aim of the Study}

Our primary aim was to find out the health problems among undergraduate medical students.

\section{Objective of the Study}

Objectives were to find out the prevalence of chronic diseases among undergraduate medical students, their consciousness of practices of exercises and yoga to keep them fit. Finally, suggestions from the students for improvement of their physical and mental health.

\section{MATERIALS AND METHODS}

We have conducted a unicentric cross-sectional study among the undergraduate medical students. This survey among the $3^{\text {rd }}$ year MBBS students of R. G. Kar Medical College with a specific questionnaire containing of 15 questions. The questions were prevalidated by faculty members. These questions were prepared in such a manner to know the present health related problems in the medical students, to know the cause of their poor attendance- is there any factor related to their physical or mental sickness? The questions were also prepared to evaluate their general health conditions and also to find out chronic disease they are suffering from, their physical and mental stress and strain directly by asking these questions.
These questions were also aimed to find out any smoking, drug or alcohol addiction and their prevalence among medical students. We also tried to find out their nutritional status by calculating their Body Mass Index (BMI). Finally, we wanted some suggestions from the students for betterment of their health in future. The questionnaires are as follows:Appendix-1

After taking informed consent, the questionnaires were distributed among the students who were willing to take part in this study. The identity of each student was kept concealed, so that they can give their opinion freely. The inclusion criteria were that the undergraduate medical students of this college is willing to take part in the study and able to fill up the questionnaires. Exclusion criteria were that the students of other classes unwilling to give written consent in the questionnaires. After filling and properly signed, the questionnaires were collected from the students and all the written information were compiled for analysis.

\section{RESULTS}

Out of 198 students 148 students (response rate 74.7\%) took part in the study, of whom 105 were male and 43 were female with a ratio of 2.44 which is corroborated with the ratio of male: female student in their class. Their mean age were 20 years. The no. of smokers were 18 and all were male only. Regarding their BMI, we have divided them into 04 (Four) classes as follows- i) Underweight- BMI less than 18.5, (ii) Normal BMI between 18.5 - 24.9, (iii) Overweight BMI between $25-29.9$ and (iv) Obese BMI more than 30. These data are shown in Table 1. Regarding the chronic illness among the medical students we got hypertension, asthma, hypothyroidism and hypotension in a few students. These have been shown in Table 2. Regarding the physical exercises among the medical students, options were Yes/No and Occasionally. Most of the answers were Occasionally (49), followed by No Exercise (31) and Regular Exercise only (08) in male students and in females it is 24 Occasionally, 13 No, and 6 were Yes. These have been shown in Table 3. Regarding the yoga practices, only 8 were male and 3 were female students practiced yoga. We also wanted to know directly whether they were suffering from mental stress and strain. The answers were positive in 26 female and negative in 17 female students and in male students it was yes in 45 students and no in 60 cases.

Regarding the frequency or number of sickness in last one year, it was shown that most of the students had fallen sick in the last year. Male students were 102 and female were 41 who had got sick in last one year, which is about $96 \%$. These have been shown in Table 4 .

Regarding the sickness absenteeism in MBBS students in the last year, 74 students were absent for 1 day, 20 students for 2 days, 4 students for 3 days and 13 students for more than 3 days and 37 students were not absent due to sickness. These data have been shown in Table 5. Regarding the opinion of the students about the Yoga/Physical Instructor, most of the students were positive (127 out of 148) for recruitment of yoga/physical instructor in the college and need for gym (139 out of 148) for improvement of their physical and mental health. 


\begin{tabular}{|c|c|c|}
\hline BMI & Students & $\mathbf{\%}$ \\
\hline Underweight (Wt < 18.5) & 13 & 8.9 \\
\hline Normal (Wt 18.5 - 24.9) & 88 & 59.5 \\
\hline $\begin{array}{c}\text { Overweight } \\
\text { (Wt 25 - 29.9) }\end{array}$ & 38 & 25.6 \\
\hline $\begin{array}{c}\text { Obese } \\
(\text { Wt > 30) }\end{array}$ & 9 & 6 \\
\hline
\end{tabular}

Table 1. BMI of Students

\begin{tabular}{|c|c|c|c|}
\hline Regular Exercise & Male & Female & Total (\%) \\
\hline Yes & 25 & 6 & $21 \%$ \\
\hline No & 30 & 13 & $29 \%$ \\
\hline Occasionally & 50 & 24 & $50 \%$ \\
\hline
\end{tabular}

Table 2. Exercise Practiced by Medical Students

\begin{tabular}{|c|c|}
\hline Diseases & No. of Students \\
\hline Hypertension & 02 \\
\hline Asthma & 13 \\
\hline Hypothyroidism & 01 \\
\hline Hypotension & 4 \\
\hline \multicolumn{2}{|c|}{ Table 3. Chronic Diseases among Students } \\
\hline
\end{tabular}

\begin{tabular}{|c|c|c|c|}
\hline No. of Sickness & Male & Female & Total \% \\
\hline One time & 42 & 18 & $40.5 \%$ \\
\hline Two times & 33 & 13 & $31 \%$ \\
\hline Three times & 12 & 6 & $12.2 \%$ \\
\hline More than three & 15 & 4 & $12.8 \%$ \\
\hline None & 3 & 2 & $3.5 \%$ \\
\hline Table 4. Number of Sickness within One Year \\
\hline
\end{tabular}

\begin{tabular}{|c|c|c|c|}
\hline Sickness Absenteeism & Male & Female & Total (\%) \\
\hline 1 Time & 52 & 22 & $50 \%$ \\
\hline 2 Times & 12 & 8 & $14 \%$ \\
\hline 3 Times & 1 & 3 & $2.5 \%$ \\
\hline More Than 3 Times & 11 & 2 & $8.5 \%$ \\
\hline None & 29 & 8 & $25 \%$ \\
\hline
\end{tabular}

Table 5. Sickness Absenteeism among Medical Students

\section{DISCUSSION}

It was seen that most of the students belonged to normal BMI group; overweight and obesity was $25.6 \%$ and $6 \%$ respectively (Table 1), which corroborate with similar study conducted among 148 first year MBBS Students of S. Nijalingappa Medical College, Bagalkot, of 2013 Batch. In their study, prevalence of overweight and obesity was $16.22 \%$ and $3.38 \%$ respectively.(11) Most of the students were suffering from mental stress and strain and reluctant of doing regular exercise (Table 2). Exercise is considered an acceptable method for improving and maintaining physical and emotional health. A growing body of evidence supports that yoga benefits physical and mental health via downregulation of the Hypothalamic-Pituitary-Adrenal (HPA) axis and the sympathetic nervous system.(12) In our study, it was found that only few students practiced Yoga (11 out of 148). As a result, they suffered from different kinds of illness (Table 3, Table 4) and were absent from the college (Table 5) and ultimately a victim of chronic ill-health. Lack of exercise and
Yoga decreases insulin secretion and decreases glucose tolerance, which may cause diabetes mellitus like disease.(13)

It is good that only very few students were smokers (18 only). Most of the students agreed that excessive lessons in their curriculum were the barrier to take regular exercise for their fitness and this is why they need Gym and/or Yoga instructor in the college.(14) If they are unable to overcome the mental stress and strain they will suffer from nervous breakdown and unwanted anxiety, depression and dissociation will occur, ultimately their performance will decrease.(15) It is probable that Health is Wealth. These students are wealth of our society and if they suffer from various diseases they will not be able to serve the society properly. So, it is our duty to look after the physical infirmity and mental health of these students for better development of the society.

\section{CONCLUSION}

So, it is seen that lack of regular exercise may cause overweight, ill-health and in future they may be a victim of chronic diseases like diabetes, hypertension, obesity or asthma. We may conclude that development of gymnasium and recruitment of Gym and Yoga instructor in this medical college is a prime need and also to ensure that students must take regular exercise or practice Yoga for their bright future.

Limitation of this study- this is a unicentric crosssectional study. Only few students participated in this study. The opinion of medical students of other colleges may be required to come to a definite conclusion before implementation of any health programme. This study is only a few steps in a long journey of health improvement of medical students.

\section{REFERENCES}

[1] Tremblay MS, Colley RC, Saunders TJ, et al. Physiological and health implications of a sedentary lifestyle. Applied Physiology, Nutrition, and Metabolism 2010;35(6):725-40.

[2] de Groot GC, Fagerström L. Older adults' motivating factors and barriers to exercise to prevent falls. Scandinavian Journal of Occupational Therapy 2011;18(2):153-60.

[3] Malina R. Physical activity and health of youth. Constanta: ovidius university annals, series physical education and sport/science, movement and health. 2010.

[4] Greg G. What is fitness? Cross Fit Journal 2002.

[5] Physical Activity Guidelines for Americans. Office of disease prevention and health promotion 2008.

[6] Haskell WL, Troiano RP, Hammond JA, et al. Physical activity and physical fitness. American Journal of Preventive Medicine 2012;42(5):486-92.

[7] Chakaravertty B, Parkavi K, Coumary SA, et al. Antepartum cardiorespiratory fitness (CRF) quantification by estimation of maximal oxygen consumption (Vo2 max) in pregnant South Indian women. J Indian Med Assoc 2012;110(4):214-7. 
[8] Kruijsen-Jaarsma M, Révész D, Bierings $M B$, et al. Effects of exercise on immune function in patients with cancer: a systematic review. Exercise Immunology Review 2013;19:120-43.

[9] Kasapis C, Thompson PD. The effects of physical activity on serum C-reactive protein and inflammatory markers: a systematic review. Journal of the American College of Cardiology 2005;45(10): 1563-9.

[10] Westcott WL, La Loud RR. Strength for fat loss training. American Fitness 2014;32(1):18-22.

[11] Kalasker PS, Dorle AS, Vetri S. A cross sectional study on obesity among first year MBBS students of S.Nijalingappa medical college, Bagalkot. National Journal of Community Medicine 2015;6(1):108-11.
[12] Ross A, Thomas S. The health benefits of yoga and exercise: a review of comparison studies. The journal of alternative and complementary medicine volume 2010;16(1):3-12.

[13] Heath GW, Gavin JR, Hinderliter JM, et al. Effects of exercise and lack of exercise on glucose tolerance and insulin sensitivity. J Appl Physiol 1983;55(2):512-7.

[14] Larry DJ, Benjamin G, Zhengzhen W, et al. Chronic disease and the link to physical activity. Journal of sport and Health Science 2013;2(1):3-11.

[15] Rapport, LJ, Todd RM, Lumley MA, et al. The diagnostic meaning of nervous breakdown among lay populations. J Pers Assess 1998;71(2):242-52. 